\title{
Postdispersal Weed Seed Predation by Crickets in a Rice Paddy Field after Irrigation Water Recedes
}

\author{
Minoru ICHIHARA ${ }^{1 *}$, Hidehiro INAGAKI ${ }^{1}$, Kazuo MATSUNO $^{1}$, \\ Chieko SAIKI ${ }^{1}$, Shunsuke MIZUMOTO ${ }^{2}$, Shou YAMAGUCHI ${ }^{2}$, \\ Masayuki YAMASHITA ${ }^{2}$ and Hitoshi SAWADA ${ }^{2}$ \\ ${ }^{1}$ Shizuoka Prefectural Research Institute of Agriculture and Forestry (Iwata, Shizuoka 438-0803, \\ Japan) \\ ${ }^{2}$ Faculty of Agriculture, Shizuoka University (Shizuoka, Shizuoka 422-8529, Japan)
}

\begin{abstract}
In this study, the relationship between the predation of weed seed by crickets and the distance from the edge of paddy fields after the irrigation water receded was investigated. In September 2011, the activity density of crickets and invertebrate seed predation were investigated twice in a paddy field at distances of $0,5,10$, and $15 \mathrm{~m}$ from the field edge, and on a paddy levee. The activity density of all cricket species in the field was 2.8-4.6 individuals/trap/day (first trial) and 2.4-6.0 individuals/trap/ day (second trial), with no significant difference in activity density between the examined distances from the field edge. However, the cricket species differed in their spatial distribution. The activity density of Teleogryllus emma peaked at $5 \mathrm{~m}$ from the field edge, whereas that of Velarifictorus micado peaked $15 \mathrm{~m}$ from the edge. In contrast, the activity density of Loxoblemmus spp., including $L$. campestris, was higher on the paddy levee than in the field. The proportion of invertebrate seed predation on Echinochloa crus-galli var. crus-galli (23.9-40.9\%/day) and Lolium multiflorum (81.0$98.8 \%$ /day) did not differ significantly between the examined distances from the field edge. Camera recordings showed crickets to be the predominant invertebrate seed predators. These results suggest that crickets can help deplete weed seed banks over a large portion of paddy fields.

Discipline: Weed control

Additional key words: biological weed control, paddy weed, seed predator, seedbank depletion
\end{abstract}

\section{Introduction}

Postdispersal seed predation by invertebrates, including crickets and carabid beetles, is one of the main causes of weed seed mortality, and may contribute to biological weed control in farmlands ${ }^{7,9,10,18,20,21,22,25}$. Recently, the number of quantitative studies of activity density of invertebrate seed predators $3,5,6,18,23$, weed seed predation by invertebrates $5,6,7,18,20,21,22,23$ and the impact of seed predation on weed population dynamics ${ }^{22}$ in upland fields have increased, primarily in Europe and the United States. However, knowledge of postdispersal weed seed predation in paddy fields remains very limited ${ }^{4}$. In monsoon Asia, including Japan, much of the farmland is occupied by paddy fields for rice cultivation. Improved understanding of the dynamics of invertebrate seed predators and seed predation by these predators in the paddy fields is essential before seed predation can be used as a form of biological weed control in paddy fields.

Crickets and carabid beetles are important seed predators in paddy areas in Japan ${ }^{9,10,11}$. Crickets ${ }^{11}$ and granivorous carabids such as Harpalus ${ }^{12,13}$ inhabit the margins of rice paddy fields, including the paddy levees that surround the fields to retain water, during the summer crop-growing season because the field interiors are flooded with irrigation water. These insects, especially crickets, have a high ability to feed on seeds ${ }^{3,14,24}$ and can contribute to biological weed control if present in large numbers ${ }^{5,7,10,18}$. Teleogryllus emma (Ohmachi et Matsuura), a widespread field cricket in Japan, feeds on the seeds of Lolium multiflorum Lam., a non-native grass weed that grows on paddy levees ${ }^{10}$. T. emma strongly suppress the seedling emergence of L. multiflorum in environments with high cricket density ${ }^{10}$. Grass weeds, such as L. multiflorum, often infest paddy levees and seriously damage

*Corresponding author: e-mail minoru1_ichihara@pref.shizuoka.lg.jp

Received 10 January 2013; accepted 20 May 2013. 
rice production because they are host plants for rice bugs that cause pecky rice grains ${ }^{8}$. Crickets can contribute substantially to the depletion of grass-weed seed banks on paddy levees.

The paddy fields are drained before the rice harvest. After drainage, the seeds of summer weeds, such as Echinochloa crus-galli (L.) P. Beauv. var. crus-galli, a noxious paddy weed, are shed in the field interior. Crickets may help suppress weeds in the paddy field interior if they penetrate into the paddy fields after the irrigation water recedes. An important consideration when using crickets for the biological control of weeds within paddy fields is the distance that the crickets penetrate into the fields. However, the penetration distance of crickets into paddy fields is unknown. There are various cricket species in paddy areas, and an understanding of the spatial distribution of each cricket species after the irrigation water recedes is needed. Furthermore, the spatial variation in the intensity of seed predation in paddy fields must also be determined. In this study, we investigated the relationships between distance from the field edge, activity density of crickets, and intensity of invertebrate seed predation within a paddy field after the irrigation water receded.

\section{Materials and methods}

\section{Experimental site}

Experiments were conducted in a paddy field in Gotemba City, Shizuoka Prefecture, Japan (field size: 17 $\times 95 \mathrm{~m}, 35^{\circ} 19^{\prime} \mathrm{N}, 138^{\circ} 55^{\prime} \mathrm{E}, 505 \mathrm{~m}$ above sea level) in 2011. The paddy field was located in a large-scale paddy area after farmland consolidation. On part of the paddy field levee, ground cover plants Phyla canescens $(65 \mathrm{~m}$ long and $2 \mathrm{~m}$ wide) and Phlox subulata (30 $\mathrm{m}$ long and 2 $\mathrm{m}$ wide) were planted for weed suppression (Fig. 1). These cover plants were transplanted to the levee in 2008 by the local government to demonstrate and promote their practical application for weed control. Crickets are known to be abundant in the planted area of the levee (Ichihara M., 2011, unpublished data). In the paddy field, rice (cv. Koshihikari) was planted on May 15 and harvested in early October. The planting density was 18.5 hills $\mathrm{m}^{-2}$ and the field was drained on August 30. Weeds within the field were chemically controlled by the post-emergence application of butachlor (1.00 kg ai/ha) and cyhalofop-butyl + simetryn + benfuresate + MCPB $(0.15+0.45+0.60+$ $0.24 \mathrm{~kg}$ ai/ha). In late May, early July and late August, the weeds on the levee were mowed to a height above the cover plants, leaving the cover plants intact, and no herbicides were applied, nor any insecticides to either the field interior or the levee. In winter, the paddy field was fallow every year.

\section{Cricket density and seed predation}

The relationships between distance from the field edge in contact with the levee covered by P. canescens, activity density of crickets, and intensity of invertebrate seed predation were investigated on September 12-13 (first trial) and September 15-16 (second trial). These periods coincided with the shedding of seeds by summer weeds and the adult stage of crickets. To minimize the penetration of the paddy field by crickets from other levees, a polyethylene mesh (mesh size: $0.16 \mathrm{~cm}^{2}, 40 \mathrm{~cm}$ high) was set at the edges of the field that were in contact with levees other than that covered by P. canescens. The mesh was set in place on August 5, before the irrigation water receded (Fig. 1). Further, the paddy field was divided by the mesh at the boundary between the P. canescens and $P$. subulata on the levee (Fig. 1). The mesh was fixed by sticking it to poles set up at $2 \mathrm{~m}$ intervals, while the bottom of the mesh was fixed to the soil surface by metal stakes at $0.5 \mathrm{~m}$ intervals.

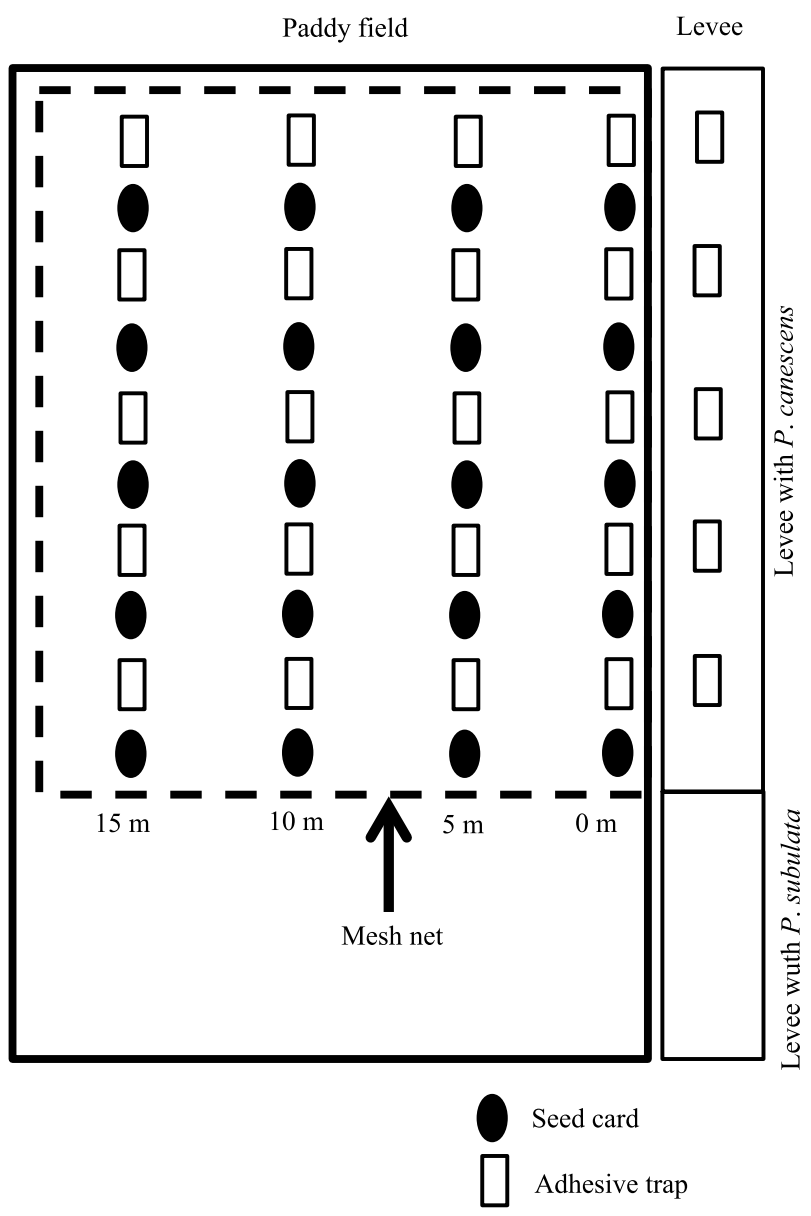

Fig. 1. Placement of adhesive traps and seed cards in the interior and levee of a paddy field 
The activity density of crickets and invertebrate seed predation were investigated within the field using adhesive traps $(10 \times 16 \mathrm{~cm}$ cockroach traps, Earth Chemical Co., Ltd., Tokyo, Japan) and seed cards ${ }^{20,21}$, respectively, that were set on the inter-row space at distances of $0,5,10$ and $15 \mathrm{~m}$ from the field edge (Fig. 1). Five traps interspersed with 5 seed cards were placed in a line at each distance, at intervals of at least $3 \mathrm{~m}$. To investigate cricket density on the levee, five traps placed more than 3 $\mathrm{m}$ apart were placed in a line on the levee. The seed cards were prepared by spraying sand cloth $(6 \times 7 \mathrm{~cm}$, grain size 60, Bell Star Abrasive Mfg. Co., Ltd., Nara, Japan) with repositionable glue (Spray Adhesive 55; Sumitomo 3M Limited, Tokyo, Japan) and applying 50 seeds. The exposed glue on the seed cards was covered in fine sand. In the first trial, seeds of L. multiflorum, which crickets consume without avoidance ${ }^{9,10}$, were used to appropriately evaluate the seed predation intensity at each distance from the field edge. In the second trial, seeds of E. crusgalli var. crus-galli, a noxious paddy weed, were used. We used exclosures to prevent vertebrate seed predators, such as birds and rodents, from accessing the seeds. An area with a radius of $10 \mathrm{~cm}$ around each seed card was surrounded using metal wire mesh (size, $2.6 \mathrm{~cm}^{2}$; height, $10 \mathrm{~cm}$ ), and the upper part of the mesh was covered using a plastic sieve (mesh size, $0.03 \mathrm{~cm}^{2}$ ). Each experimental period was 1 day long, based on the results of a preliminary experiment that indicated very high cricket density and seed predation at this experimental site. The adhesive traps and seed cards were in place from 15:00 the first day to 9:00 the next day of each experimental period because crickets were observed to feed on seeds mainly at night (Ichihara M., 2011, unpublished data). During the experimental periods, the weather was clear, and temperatures ranged from 20.5 to $27.3^{\circ} \mathrm{C}$ (first trial) and 18.9 to $27.1{ }^{\circ} \mathrm{C}$ (second trial). The paddy field was completely drained during these periods, and there was no stagnant water on the soil surface that was flat.

Three control seed cards were placed within the field during each experimental period to assess seed loss due to rain, wind, or loss of adhesion. Each control card was placed at the bottom of a cubic cage (side length: 15 $\mathrm{cm}$ ) of metal wire mesh (mesh size: $0.25 \mathrm{~cm}^{2}$ ), and the cage was supported $10 \mathrm{~cm}$ above the ground by four metal poles". The upper part of each pole was lined with double-sided adhesive tape to keep seed predators out of the cage.

To identify the invertebrate seed predators, a digital time-lapse camera (GardenWatchCam; Brinno Incorporated, Palm City, FL, USA) was set up above one seed card at each distance from the field edge. The image-acquisition interval was set to $10 \mathrm{~s}$ and the cameras re- mained in place throughout each experimental period. An 8-cm-diameter hole was cut in the upper part of the sieve covering the seed card under each camera so that photographs of the seed predators could be taken through the sieve. To allow nighttime photography, each camera was set for low-light recording and the seed card under each camera was illuminated with constant red light from an LED flashlight (BF-158BF-W; Panasonic Corporation, Osaka, Japan) covered by a red cellophane filter.

\section{Data analysis}

The number of seeds remaining on the seed cards was converted into the proportion of seed predation relative to the number of seeds remaining on the control cards using Abbott's correction formula, $M=(C-R) / C$, where $M$ is the proportion of seed predation, $R$ is the number of seeds remaining on the cards, and $C$ is the number of seeds remaining on the control cards ${ }^{1}$. Captured crickets were identified to the species level, and the number of individuals was recorded. Differences in seed predation and cricket density between test distances were examined using Tukey's honestly significant difference test for multiple comparisons. Cricket density on the levee was also included in the statistical analysis. Furthermore, differences in the densities of T. emma, Velarifictorus micado (Saussure 1877), and Loxoblemmus spp. at each distance from the field edge and on the paddy levee were separately evaluated. Prior to performing statistical analyses, arcsine and log transformations were used to normalize the percentage data and count data, respectively. All statistical analyses were performed using R (Version 2.15.1 $)^{19}$.

\section{Results}

T. emma, V. micado, Loxoblemmus spp. including $L$. campestris Matsuura, 1988, Mitius minor (Shiraki, 1913), Dianemobius nigrofasciatus (Matsumura, 1904), Polionemobius mikado (Shiraki, 1913), and Pteronemobius ohmachii (Shiraki, 1930) were captured on the levee of and within the paddy field (Fig. 2 (a)-(b)). The activity density of all cricket species in the paddy field was 2.8 4.6 individuals/trap/day (first trial) and 2.4-6.0 individuals/trap/day (second trial), and there was no significant difference in activity density between the examined distances from the field edge. The activity density of all cricket species on the paddy levee was 7.6 individuals/ trap/day (first trial) and 7.2 individuals/trap/day (second trial).

Cricket species differed in their spatial distribution (Fig. 3 (a)-(c)). The activity density of T. emma peaked (3.4 individuals/trap/day) at $5 \mathrm{~m}$ from the field edge and 
was also relatively high (2.8 individuals/trap/day) on the paddy levee in the first trial (Fig. 3 (a)). The activity density of $V$. micado rose with increasing distance from the field edge and peaked at $15 \mathrm{~m}$ from the field edge (1.6-1.8 individuals/trap/day; Fig. 3 (b)). In contrast, the activity density of Loxoblemmus spp. was higher on the paddy levee (4.0-4.4 individuals/trap/day) than in the field (0.30.7 individuals/trap/day; Fig. 3 (c)). Granivorous carabid

(a) First trial

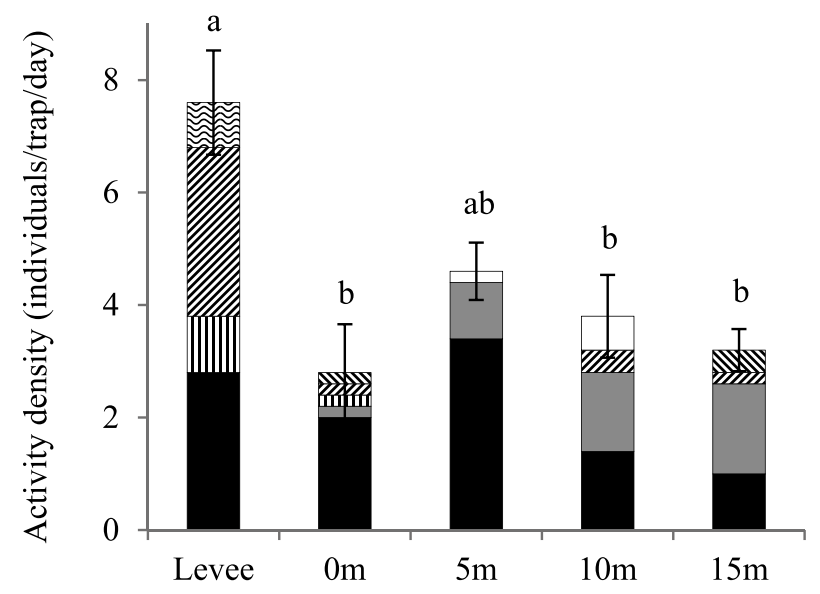

(b) Second trial

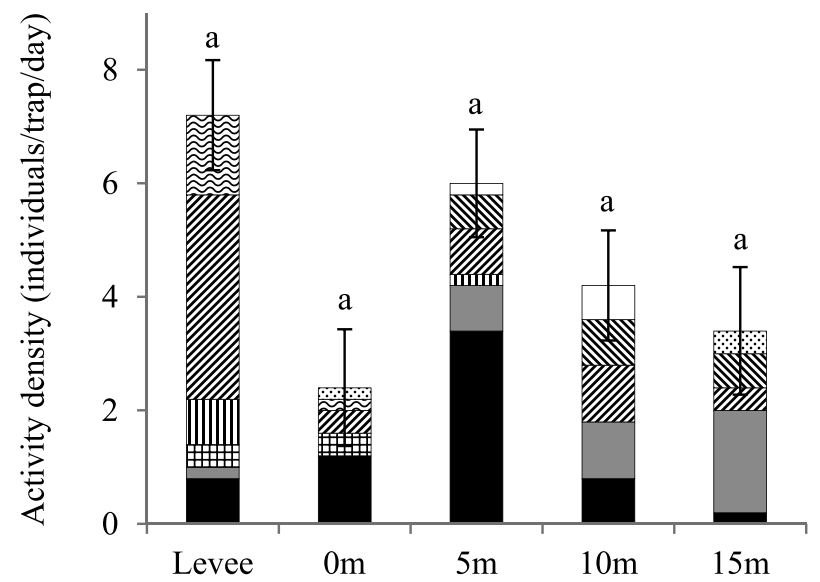

Distance from field edge

Cricket species: $\square$ : unidentified, 7 : P. ohmachii, 图: P. mikado, $\mathbb{N}:$ D. nigrofasciatus, $\mathscr{\mathbb { A }}:$ Loxoblemmus spp., 四: L. campestris, 国: minor, $\square:$ V. micado, $\mathbf{\square}$ : T. emma

Fig. 2. Activity density of all cricket species within the field at distances of $0,5,10$ and $15 \mathrm{~m}$ from the field edge, and on the paddy levee on (a) September 12-13, the first trial and (b) September 15-16, the second trial

Means that differ significantly at $P<0.05$, based on Tukey's honestly significant difference test, are identified by different letters. Vertical bars represent the standard errors of the means. beetles such as Harpalus were not captured in either the field interior or the levee. Invertebrate seed predation

(a) T. emma

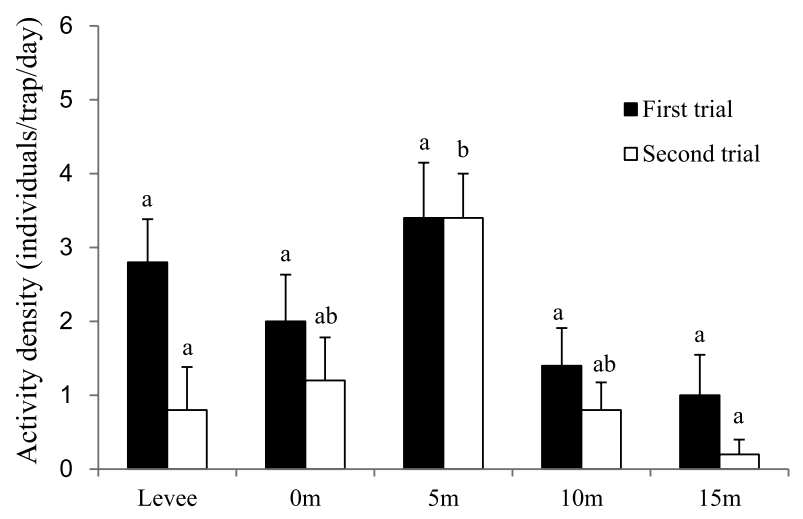

(b) V. micado

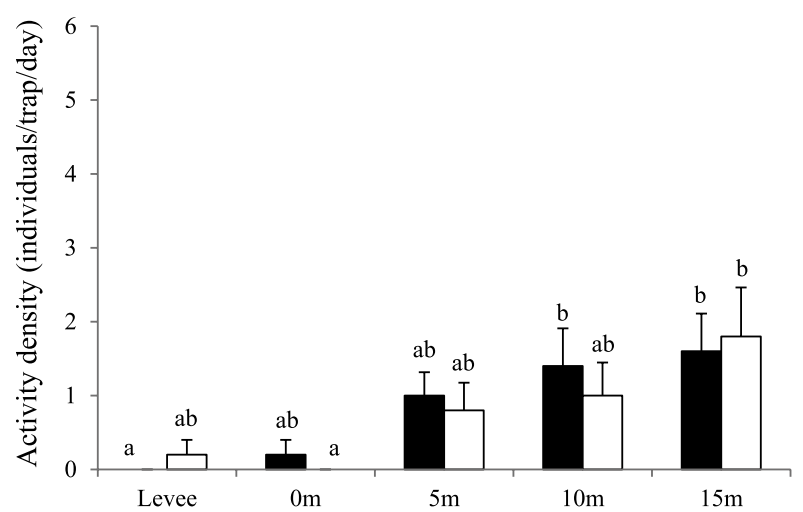

(c) Loxoblemmus spp.



Distance from field edge

Fig. 3. Activity density of (a) T. emma, (b) V. micado and (c) Loxoblemmus spp. within the field at distances of 0 , 5,10 and $15 \mathrm{~m}$ from the field edge, and on the paddy levee on September 12-13, the first trial (black bars) and September 15-16, the second trial (white bars)

Within each trial, those means that differ significantly at $P<0.05$, based on Tukey's honestly significant difference test, are identified by different letters. Vertical bars represent the standard errors of the means. 
did not differ significantly at different distances from the field edge (Fig. 4 (a)-(b)). The proportion of seed predation on L. multiflorum was $81.0-98.8 \%$ /day during the first trial (Fig. 4 (a)), while that on E. crus-galli var. crusgalli was 23.9-40.9\%/day during the second trial (Fig. 4 (b)). The proportion of seed loss in the control seed cards was 3.3 (first trial)-6.7 (second trial) \%/day. Camera recordings showed that crickets were the predominant invertebrate seed predators. In 51840 pictures recorded by the cameras, the number of pictures on which crickets were observed on the seed cards was 3934, and that of pictures on which the carabid beetle was observed was 1 . Seed predation other than crickets was not observed.

\section{(a) First trial}

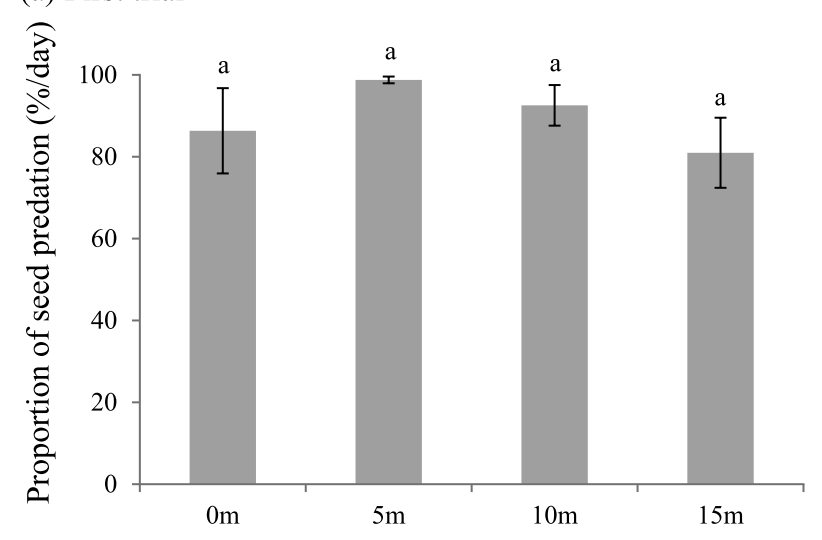

(b) Second trial

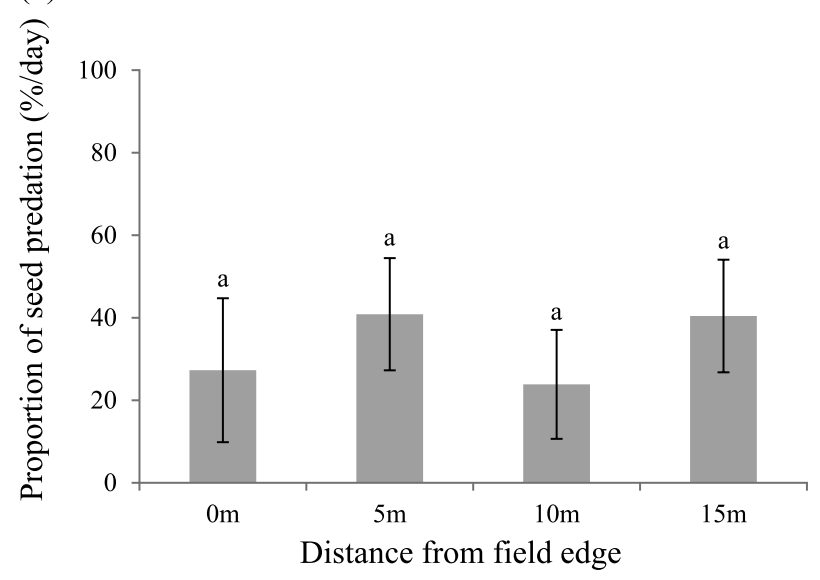

Fig. 4. Proportion of invertebrate seed predation on (a) $L$. multiflorum (September 12-13, the first trial) and (b) E. crus-galli var. crus-galli (September 15-16, the second trial) within the field at distances of 0,5 , 10 and $15 \mathrm{~m}$ from the field edge

Means that differ significantly at $P<0.05$, based on Tukey's honestly significant difference test, are identified by different letters. Vertical bars represent the standard errors of the means.

\section{Discussion}

This study revealed the relationship between weed seed predation by crickets and distance from the edge within a paddy field after the irrigation water receded. Within the field, crickets were widely distributed at 0 to $15 \mathrm{~m}$ from the field edge (Fig. 2 (a)-(b)). Furthermore, weed seeds placed on the soil surface were consumed at a distances of 0 to $15 \mathrm{~m}$ from the field edge (Fig. 4 (a)-(b)) and crickets were the predominant invertebrate seed predators. These results suggest that crickets can help deplete weed seed banks over a large portion of rice paddy fields.

The activity density of all cricket species and the intensity of invertebrate seed predation did not differ significantly at different distances from the field edge (Fig. 2 (a)-(b), Fig. 4 (a)-(b)). Crickets were homogeneously distributed within the paddy field, which probably resulted in spatially homogeneous seed predation intensity. In Japan, the standard size of consolidated paddy fields is $3000 \mathrm{~m}^{2}(30 \times 100 \mathrm{~m})$. Because crickets migrate at least $15 \mathrm{~m}$ from the field edge into the field interior, crickets may be homogeneously distributed and consume weed seeds throughout paddy fields that are $30 \mathrm{~m}$ wide. In the tropical climate of the Philippines, fire ants (Solenopsis geminata Fabricius 1804) are the predominant invertebrate seed predators, and remove many seeds of Echinochloa colona (L.) Link from paddy fields ${ }^{4}$. In contrast, our study indicated that crickets are the predominant invertebrate seed predators in this part of Japan, and suggested that they can contribute to biological weed control in paddy fields. Although the sampling dates differed slightly, the proportion of seed predation on L. multiflorum and E. crus-galli var. crus-galli tended to differ (8199 and $24-41 \%$ /day, respectively), suggesting that the seed preference of crickets may differ between these weed species. Although the seed preference of crickets can influence plant community structures in farmlands ${ }^{2}$, the seed preferences of Japanese crickets are unknown and must thus be investigated for the seeds of paddy weed species in future studies.

Since cricket species had different spatial distributions (Fig. 3 (a)-(c)), the habitat preferred by each cricket species in the paddy field after the irrigation water recedes is also considered to differ. During the study period, the rice was seed setting (vegetation height: ca. 80 $\mathrm{cm}$ ) and small-sized weeds such as Centipeda minima (L.) A. Braun et Asch. and Cyperus flaccidus R. Br grew sparsely on the wet paddy field soil. In contrast, the paddy levee was dominated by $P$. canescens (vegetation height: ca. $10 \mathrm{~cm}$ ). L. campestris is known to prefer a relatively dry habitat ${ }^{15}$, whereas $T$. emma tends to inhabit 
both dry and wet habitats ${ }^{16}$. Thus, the difference in spatial distribution between these cricket species may be partly attributable to these habitat preferences. The reason that $V$. micado activity density rose with increasing distance from the field edge is unknown. However, this study was conducted in only one paddy field. The spatial distribution and population density of crickets might be influenced by environment conditions of paddy fields and levees, such as the soil moisture and vegetation etc. Therefore, it is necessary to conduct the study in other paddy fields under various environment conditions in future.

The results of this study suggest that crickets can be efficient biological control agents for weeds in paddy fields. The contribution of seed predation by crickets to biological weed control may be enhanced by increasing the population density of crickets in the paddy fields. Ichihara et al. $(2012 \mathrm{a})^{10}$ reported that with increasing cricket density, weed seed predation also rises, while weed seedling emergence declines. Paddy levees are an important habitat for crickets during the summer crop-growing season and can serve as a source of cricket populations for field colonization ${ }^{11}$. The population density of crickets could be enhanced by developing vegetation management strategies for paddy levees to conserve crickets $^{10,11}$. Furthermore, the proportion, shape, and spatial distribution of grasslands, such as paddy levees, in agricultural landscapes may influence the cricket density and seed predation. The intensity of seed predation in cornfields varies according to the structure of the surrounding landscape ${ }^{17}$. However, the relationship between seed predation in paddy fields and their surrounding landscapes has not yet been studied. Landscape factors determining cricket density and seed predation intensity in paddy fields must be investigated in future.

\section{Acknowledgments}

We gratefully acknowledge SEIKAN Co., Ltd. for identifying the crickets. We also thank M. Mizuno, $\mathrm{H}$. Ito, H. Iwata, K. Suzuki, Y. Washitaki and Y. Tanno for their assistance in the field and laboratory and farmer I. Yokoyama who allowed us to use the paddy field.

\section{References}

1. Abbott, W. S. (1925) A method of computing the effectiveness of an insecticide. Econ. Entomol., 18, 265-267.

2. Brust, G. E. (1994) Seed-predators reduce broadleaf weed growth and competitive ability. Agric. Ecosyst. Environ., 48, 27-34.

3. Carmona, D. M. et al. (1999) Gryllus pennsylvanicus (Orthoptera: Gryllidae): laboratory weed seed predation and within field activity-density. J. Econ. Entomol., 92, 825829.

4. Chauhan, B. S. et al. (2010) Post-dispersal predation of weed seeds in rice fields. Weed Res., 50, 553-560.

5. Davis, A. S. \& Liebman, M. (2003) Cropping system effects on giant foxtail (Setaria faberi) demography: I. Green manure and tillage timing. Weed Sci., 51, 919-929.

6. Davis, A. S. \& Raghu, S. (2010) Weighing abiotic and biotic influences on weed seed predation. Weed Res., 50, 402412.

7. Heggenstaller, A. H. et al. (2006) Seasonal patterns in postdispersal seed predation of Abutilon theophrasti and Setaria faberi in three cropping systems. J. Appl. Ecol., 43, 9991010.

8. Higuchi, H. (2010) Ecology and management of rice bugs causing pecky rice. Nippon ouyou doubutsu konchu gakkaishi (Jpn. J. Appl. Entomol. Zool.), 54, 171-188 [In Japanese].

9. Ichihara, M. et al. (2011) Quantifying the ecosystem service of non-native weed seed predation provided by invertebrates and vertebrates in upland wheat fields converted from paddy fields. Agric. Ecosyst. Environ., 140, 191-198.

10. Ichihara, M. et al. (2012a) Post-dispersal seed predation by Teleogryllus emma (Orthoptera: Gryllidae) reduces the seedling emergence of a non-native grass weed, Italian ryegrass (Lolium multiflorum Lam.). Weed Biol. Manage., 12, 131-135.

11. Ichihara, M. (2012b) Biological interaction between weeds and insect seed predators in agro-ecosystems: applicability to IPM. Shokubutsu boueki (Plant Prot.), 66, 216-219 [In Japanese].

12. Kagawa, Y. et al. (2008) Species composition of ground beetles (Coleoptera: Carabidae and Brachinidae) in an agricultural landscape consisting of a mosaic of vegetations types. Konchu (new series) (Jpn. J. Ent. (N.S.)), 11, 75-84 [In Japanese with English summary].

13. Lee, C. et al. (2008) Change in structure of ground-beetle assemblage on levee of paddy field after the paddy reclamation in southern Osaka, central Japan. Konchu to sizen (Nat. Insects), 43, 6-10 [In Japanese].

14. Lundgren, J. G. \& Rosentrater, K. A. (2007) The strength of seeds and their destruction by granivorous insects. Arthropod Plant Interact., 1, 93-99.

15. Matsuura, I. (1977) Japanese crickets (3). Konchu to sizen (Nat. Insects), 12, 23-27 [In Japanese].

16. Matsuura, I. (1978) Japanese crickets (4). Konchu to sizen (Nat. Insects), 13, 17-22 [In Japanese].

17. Menalled, F. D. et al. (2000) Post-dispersal weed seed predation in Michigan crop fields as a function of agricultural landscape structure. Agric. Ecosyst. Environ., 77, 193-202.

18. O'Rourke, M. E. et al. (2006) Post-dispersal weed seed predation by invertebrates in conventional and low-externalinput crop rotation systems. Agric. Ecosyst. Environ., 116, $280-288$.

19. R Development Core Team (2012) R: A language and environment for statistical computing. R Foundation for Statistical Computing, Vienna, Austria. http://www.r-project. org/

20. Westerman, P. R. et al. (2003a) Annual losses of weed seeds due to predation in organic cereal fields. J. Appl. Ecol., 40, 824-836. 
21. Westerman, P. R. et al. (2003b) Relative importance of vertebrates and invertebrates in epigeaic weed seed predation in organic cereal fields. Agric. Ecosyst. Environ., 95, 417425 .

22. Westerman, P. R. et al. (2005) Are many little hammers effective? Velvetleaf (Abutilon theophrasti) population dynamics in two- and four-year crop rotation systems. Weed Sci., 53, 382-392.
23. Westerman, P. R. et al. (2008) Density-dependent predation of weed seeds in maize fields. J. Appl. Ecol., 45, 1612-1620.

24. White, S. S. et al. (2007) Feeding preferences of weed seed predators and effect on weed emergence. Weed Sci., 55, 606-612.

25. Zhang, J. et al. (1997) Insect predation of seeds and plant population dynamics. MAFES Tech. Bull., 163, 1-32. 